\title{
NONLINEARITY IN FINANCIAL SERIES: TRANSITORY OR PERMANENT?
}

\author{
Christian E. Espinosa M. \\ Universidad de Santiago de Chile | Facultad de Administración y Economía \\ christian.espinosa.m@usach.cl \\ Juan Gorigoitía \\ Universidad de Santiago de Chile | Facultad de Administración y Economía \\ juan.gorigoitia@usach.cl
}

\section{Carlos Maquieira}

Universidad del Pacífico | Escuela de Posgrado carpat.villa@gmail.com

\begin{abstract}
In this article we present evidence that nonlinearity episodes in financial series are more permanent than transitory. At the same time, these episodes show different behaviors depending on the market analyzed, which would indicate that they are not completely synchronized. On the other hand, the size of the window for detecting nonlinear episodes has an impact on the number of nonlinear windows found, as well as the percentage of nonlinear windows with respect to the total number of windows, confirming a window size effect. The results strongly invalidate the efficient markets hypothesis and forcefully explain the incapability to predict its future values.
\end{abstract}

Keywords: Hinich Test, Rolling Method, Stock Indices, Window Size Effect

\section{Resumen}

En este artículo presentamos evidencia de que los episodios de no linealidad en las series financieras son más permanentes que transitorios. Al mismo tiempo, estos episodios muestran diferentes comportamientos según el mercado analizado, lo que indicaría que no están completamente sincronizados. Por otro lado, el tamaño de la ventana para detectar episodios no lineales afecta el número de ventanas no lineales encontradas, así como el porcentaje de ventanas no lineales con respecto al número total de ventanas, lo que confirma el efecto del tamaño de la ventana. Los resultados invalidan fuertemente la hipótesis de mercados eficientes y explican con fuerza la incapacidad de predecir sus valores futuros. 
Palabras claves: Prueba de Hinich, Modelo Rolling, Índices accionarios, Efecto de tamaño de ventana.

\section{Intoducción}

Many studies have reported nonlinear behavior in different financial assets series all around the world, such as stocks, currencies, bonds and commodities, and with several time frames. For example, in North America (Hinich and Patterson, 1985; Scheinkman and LeBaron, 1989; Hsieh, 1991; Brock et al., 1996); in European markets (Abhyankar et al., 1995; Opong et al., 1999; Kosfeld and Robé, 2001; Todea and ZoicasIenciu, 2008); in Asian markets (Ammermann and Patterson, 2003; Lim and Hinich, 2005); and in Latin American markets (Bonilla et al., 2006; Bonilla et al., 2008; Bonilla et al., 2010; Bonilla et al., 2011; Espinosa et al., 2013).

The Hinich test is commonly used to detect nonlinear episodes. Generally speaking, financial assets series present behavior characterized by transient epochs of dependencies surrounded by long periods of white noise, as has been reported (Ammermann and Patterson, 2003; Brooks et al., 2000; Lim et al. 2005; Lim et al., 2006, Bonilla et al., 2006; Bonilla et al., 2008; among others).

Recent research shows, however, that non-linearity periods that occur before nonlinear windows do exist, and that after a nonlinear window the non-linearity phenomenon does not completely dissipate but rather expands into windows in different time scales (Espinosa et al., 2013).

Following this line of thinking, the research of Espinosa et al. (2014) proceeds in a different manner than the standard approach by using non-overlapping windows in the Hinich test ${ }^{1}$, and using overlapping windows, the equivalent of using a rolling methodology ${ }^{2}$. We have found that the number of nonlinear windows increases significantly with respect to the standard method. This suggests that non-linearity is a more permanent process, rather than a transitory one, within financial series ${ }^{3}$.

Simultaneously, we modify the number of observations that make up the windows so as to be able to detect nonlinear processes and find that, as the size of the window grows, the number of nonlinear windows increases; this occurs when using either methodology. A question that arises when faced with this evidence is if the increase in nonlinear processes is a constant for other financial assets series and if its behavior is the same for different assets ${ }^{4}$.

In this article we present convincing evidence contrary to the hypothesis that financial assets series present behavior characterized by transient epochs of dependencies surrounded by long periods of white noise. On the one hand, the results

1 The Hinich standard procedure consists in dividing the full sample period into equal-length non-overlapping moving time windows. Suppose that a 50-day window length is chosen, the first window comprises the first 50 sample data points, starts from day 1 and ends on day 50 . The second window comprises observations running from day 51 through day 100. Subsequent windows will follow in a similar manner until the end of the data series is reached. However, the last window is not used if there are not 50 observations to fill that window. 2 The rolling methodology basically consists in a statistical procedure in which an $n$ sized sub-sample of a series of data is selected so that a statistic may be applied to it, in our case, the Hinich test. Thus, as new information is added, the last piece of information is omitted and the size of the sub-sample remains constant. This allows for the adding of new information to the series of financial assets disregarding the older information, which is in agreement with the adaptive expectations hypotheses. In other words, the agents adapt their decisions as new information appears, in line with the adaptive markets hypotheses (Lo, 2004; Lo, 2005).

$3 \mathrm{Lim}$, Brooks and Hinich (2006) indicate that the standard process is similar to the rolling time windows given that the window length in both approaches is fixed, the only difference lies on how the time windows move forward. This is a weak explanation considering that when non-overlapping windows are used, underlying information in the price series is omitted, potentially generating nonlinear processes.

4 Espinosa et al. (2014), only using EMBI series for Eastern Europe. 
show clear evidence that nonlinear episodes are more permanent than transitory within financial assets series. At the same time, this nonlinear process presents different behavior depending on the analyzed series. Similarly, the size of the window used to detect nonlinear episodes had an impact on the number of nonlinear windows found. Regarding this, Brooks and Hinich (1998) postulate that the window must be big enough to offer a robust statistical power and yet short enough to identify the arrival and disappearance of transient dependencies. In any case, the results are basically the same if we double or triple the window length (Brooks, Hinich and Molyneux, 2000). Brooks and Hinich (1998) suggest 35 observations as the best size of the window, while other articles employ 25 observations (Bonilla et al., 2006; Bonilla et al., 2010), 35 observations (Todea and Zoicas-Ienciu, 2008; Bonilla et al., 2008) and 50 observations (Lim, Brooks and Hinich, 2008), among others. The authors found that as the size of the window increases, the number of nonlinear windows also increases contradicting what is stated by Brooks, Hinich and Molyneux (2000), confirming a "window size effect" in financial assets series.

This article contributes to the existing literature in two aspects. First, we report substantial evidence for different financial assets series that nonlinear behavior in financial series is more permanent than transitory, which strongly explains the inability to predict its future values, and also strongly invalidates the efficient markets hypothesis ${ }^{5}$. Second, we show that this behavior is not identical for all financial assets. And Third, that the results of the Hinich test are sensitive to the selection of the size of the window for detecting nonlinear episodes.

The rest of the paper is structured as follows: Section II presents the methodology which will be used. Section III presents the data to be used in this study. Section IV presents the most relevant results. The final conclusions are presented in Section V.

\section{Methodology}

\section{Hinich Test}

The Hinich test employs non-overlapping ${ }^{6}$ data windows. If $n$ is the window length then the $\mathrm{x}$-th window is $\left\{x\left(t_{k}\right), x\left(t_{k}+1\right), \ldots, x\left(t_{k}+n-1\right)\right\}$. The next nonoverlapping window, $k+1$, is $\left\{x\left(t_{k+1}\right), x\left(t_{k+1}+1\right), \ldots, x\left(t_{k+1}+n-1\right)\right\}$, where $t_{k+1}=t_{k}+n$. The null hypothesis for each window is that $\mathrm{x}(t)$ are realizations of a stationary pure noise process that has zero bicorrelation. The alternative hypothesis is that the process generated within the window is random, with some non zero bicorrelation

5 The evidence from different papers regarding nonlinear processes in financial series has been used to show the random walk hypothesis is not met because these financial series present behavior characterized by short periods (windows) of nonlinear processes and long period of random walk. This evidence refutes the efficient markets hypothesis. Indeed, an efficient market where the price reflects all of the available information and, therefore, where it isn't possible to make future price predictions, requires random walk behavior without linear dependency. In this sense we shouldn't expect to have nonlinear windows within the data, in which case this situation in completely contrary to the evidence presented in this article. 6 Non-overlapping windows mean that they do not overlap with each other (they are independent). The Hinich test can work with different lengths of windows avoiding overlapping. 
$C x x x(r, s)=E\lfloor x(t) x(t+r) x(t+s)\rfloor$ in the $0<r<s<L$ set, where $L$ is the number of lags defining the window. The Hinich portmanteau statistics and its corresponding distribution are $^{7}$ :

$$
H=\sum_{s=2}^{L} \sum_{r=1}^{s-1}\left[\frac{G^{2}(r, s)}{T-s}\right] \sim \chi^{2}\left(\frac{(L-1) L}{2}\right)
$$

where,

$$
G(r, s)=(n-s)^{\frac{1}{2}} C_{z z z}(r, s) \text { and } C_{z z z}(r, s)=(n-s)^{-1} \sum_{t=1}^{n-s} Z(t) Z(t+r) Z(t+s)
$$

for $0 \leq r \leq s$

The $\mathrm{Z}(t)$ are standardized observations obtained by subtracting the window's sample mean and dividing by its standard deviation. The number of lags, $L$, is specified as $L=n^{b}$ with $0<\mathrm{b}<0.5$, where $b$ is a parameter chosen by the analyst. Based on Monte Carlo simulations results, the recommended use of $b$ is $b=0.4$ (Hinich and Patterson, 1985 ) in order to maximize the power of the test while ensuring a valid approximation to the asymptotic theory. In this test procedure, a window is significant if the $\mathrm{H}$ statistic rejects the null hypothesis of pure noise at the specified statistical confidence of $1 \%$.

\section{Data}

The stock market indices sample is composed of eight time series: CAC40 (France), DAX (Germany), FTS100 (United Kingdom), IBEX (Spain), IGBVL (Peru), IPC (Mexico), IPSA (Chile) and SP500 (United States). The time frame for the all indices is from January 1995 to June 2013.

The commodities spot price sample is composed of four time series: WTI, Copper, Gold and Silver. The time frame for WTI is from January 1991 to July 2013; for Copper from January 1999 to July 2013; and for Gold and Silver from January 2001 to July 2013.

The currencies spot price sample is composed of nine time series: Australian Dollar, Canadian Dollar, Euro, Swiss Franc, British Pound, Chilean Peso, Columbian Peso, Mexican Peso and Brazilian Real. The time frame for the all currencies is from January 2000 to July 2013.

The credit default swap spread sample is composed of four time series: Portugal, Ireland, Cyprus and Greece. The time frame for Portugal is from April 2003 to March 2013; for Ireland from October 2007 to March 2013; for Cyprus from September 2009 to March 2013; and for Greece from March 2003 to March 2013.

The data is transformed in the following way: , where pt is the closing price of the market stock index in day $t$, except for credit default swap spread we used the first difference. The sources for the data were Economática (Indices), Cochilco (Commodities), Chilean Central Bank (Currencies) and Bloomberg (Credit default swap spread).

7 Readers interested in a mathematical derivation of this statistic and its properties can refer to Hinich (1996). 


\section{Empirical Results}

Table 1 shows the results of the Hinich test applied to the series of residues from commodities, exchange rates, stock market indices and credit default swaps (CDS), using both the standard and rolling methodologies. The results are shown per year.

First, when the rolling method is applied, we find that the amount of nonlinear windows increases significantly when compared to the application of the traditional methodology used for calculating the Hinich test in all of the series analyzed. For example, using a traditional window size of 25 observations, the standard methodology finds 7, 7, 14 and 3 nonlinear windows for series of Commodities, Exchange Rates, Stock Indices, and CDS, respectively. However, when the rolling methodology is used on the same series, the results produce $121,146,331$, and 102 nonlinear windows respectively. These results show that the standard methodology used to detect nonlinear windows, applied in different studies (Brooks and Hinich, 1998; Bonilla et al., 2006; Lim, Brooks and Hinich, 2008; Bonilla et al., 2010, among others), underestimate the true amount of nonlinear processes in financial series. This strongly invalidates the efficient markets hypothesis and explains robustly the inability to predict future prices.

Table 1. Windowed-Test Results (per year and type of financial asset)

\begin{tabular}{|c|c|c|c|c|c|c|c|c|c|c|}
\hline \multicolumn{2}{|c|}{ Panel A: Commodities } & \multicolumn{4}{|c|}{ Rolling } & \multicolumn{5}{|c|}{ Standard } \\
\hline Year/Window & 25 & 30 & 50 & 100 & 150 & 25 & 30 & 50 & 100 & 150 \\
\hline 1991 & 2 & 6 & 12 & 39 & 45 & 0 & 0 & 1 & 1 & 1 \\
\hline 1992 & 0 & 2 & 8 & 34 & 42 & 0 & 0 & 0 & 0 & 0 \\
\hline 1993 & 0 & 0 & 3 & 14 & 7 & 0 & 0 & 0 & 0 & 0 \\
\hline 1994 & 0 & 0 & 2 & 1 & 1 & 0 & 0 & 0 & 0 & 0 \\
\hline 1995 & 0 & 2 & 8 & 9 & 18 & 0 & 0 & 0 & 0 & 0 \\
\hline 1996 & 0 & 0 & 0 & 21 & 10 & 0 & 0 & 0 & 0 & 0 \\
\hline 1997 & 0 & 2 & 3 & 4 & 4 & 0 & 0 & 0 & 0 & 0 \\
\hline 1998 & 1 & 0 & 2 & 37 & 82 & 0 & 0 & 0 & 0 & 0 \\
\hline 1999 & 0 & 1 & 0 & 0 & 3 & 0 & 0 & 0 & 0 & 0 \\
\hline 2000 & 1 & 2 & 0 & 29 & 72 & 0 & 0 & 0 & 0 & 0 \\
\hline 2001 & 10 & 8 & 51 & 118 & 139 & 0 & 0 & 2 & 2 & 3 \\
\hline 2002 & 5 & 2 & 13 & 42 & 64 & 1 & 0 & 0 & 0 & 0 \\
\hline 2003 & 7 & 11 & 46 & 98 & 150 & 0 & 0 & 1 & 1 & 1 \\
\hline 2004 & 14 & 38 & 52 & 110 & 337 & 2 & 1 & 0 & 2 & 3 \\
\hline 2005 & 0 & 0 & 6 & 21 & 87 & 0 & 0 & 0 & 0 & 0 \\
\hline 2006 & 13 & 19 & 101 & 132 & 194 & 1 & 0 & 2 & 2 & 3 \\
\hline 2007 & 10 & 16 & 49 & 93 & 215 & 0 & 0 & 3 & 1 & 1 \\
\hline 2008 & 6 & 9 & 72 & 148 & 237 & 0 & 0 & 2 & 2 & 1 \\
\hline 2009 & 7 & 1 & 3 & 82 & 243 & 0 & 0 & 0 & 0 & 2 \\
\hline 2010 & 3 & 8 & 11 & 82 & 119 & 0 & 0 & 1 & 1 & 1 \\
\hline 2011 & 40 & 69 & 165 & 401 & 471 & 2 & 1 & 2 & 3 & 2 \\
\hline
\end{tabular}


Nonlinearity in Financial Series: Transitory or Permanent?

\begin{tabular}{|c|c|c|c|c|c|c|c|c|c|c|}
\hline 2012 & 1 & 4 & 34 & 89 & 230 & 1 & 0 & 1 & 3 & 2 \\
\hline 2013 & 1 & 0 & 11 & 41 & 83 & 0 & 0 & 0 & 1 & 1 \\
\hline NL windows & 121 & 200 & 652 & 1645 & 2,853 & 7 & 2 & 15 & 19 & 21 \\
\hline $\begin{array}{l}\text { Total } \\
\text { windows }\end{array}$ & 15,622 & 15,602 & 15,522 & 15,322 & 15,122 & 628 & 521 & 312 & 154 & 103 \\
\hline Percentage & $0.77 \%$ & $1.28 \%$ & $4.20 \%$ & $10.74 \%$ & $18.87 \%$ & $1.11 \%$ & $0.38 \%$ & $4.81 \%$ & $12.34 \%$ & $20.39 \%$ \\
\hline \multicolumn{3}{|c|}{ Panel B: Exchange Rates } & \multicolumn{5}{|l|}{ Rolling } & \multicolumn{3}{|c|}{ Standard } \\
\hline Year/Window & 25 & 30 & 50 & 100 & 150 & 25 & 30 & 50 & 100 & 150 \\
\hline 2000 & 5 & 13 & 47 & 174 & 103 & 1 & 1 & 1 & 3 & 2 \\
\hline 2001 & 4 & 1 & 31 & 294 & 532 & 0 & 0 & 0 & 4 & 5 \\
\hline 2002 & 36 & 58 & 216 & 447 & 670 & 2 & 1 & 6 & 4 & 2 \\
\hline 2003 & 23 & 39 & 72 & 219 & 397 & 1 & 2 & 3 & 2 & 3 \\
\hline 2004 & 0 & 8 & 75 & 198 & 394 & 0 & 0 & 0 & 2 & 3 \\
\hline 2005 & 4 & 23 & 144 & 245 & 447 & 0 & 0 & 4 & 1 & 2 \\
\hline 2006 & 17 & 20 & 101 & 228 & 408 & 1 & 0 & 2 & 3 & 2 \\
\hline 2007 & 2 & 5 & 95 & 207 & 474 & 0 & 0 & 2 & 1 & 2 \\
\hline 2008 & 26 & 38 & 143 & 600 & 779 & 1 & 1 & 3 & 7 & 0 \\
\hline 2009 & 17 & 33 & 29 & 164 & 638 & 0 & 0 & 0 & 1 & 7 \\
\hline 2010 & 3 & 23 & 69 & 269 & 358 & 0 & 2 & 2 & 3 & 3 \\
\hline 2011 & 9 & 11 & 71 & 321 & 495 & 1 & 0 & 0 & 1 & 1 \\
\hline 2012 & 0 & 0 & 41 & 186 & 494 & 0 & 0 & 2 & 1 & 3 \\
\hline 2013 & 0 & 0 & 4 & 78 & 234 & 0 & 0 & 0 & 0 & 1 \\
\hline NL windows & 146 & 272 & 1,138 & 3,63 & 6,423 & 7 & 7 & 25 & 33 & 36 \\
\hline $\begin{array}{l}\text { Total } \\
\text { windows }\end{array}$ & 30,282 & 30,237 & 30,057 & 29,607 & 29,157 & 1,215 & 1,008 & 603 & 297 & 198 \\
\hline Percentage & $0.48 \%$ & $0.90 \%$ & $3.79 \%$ & $12.26 \%$ & $22.03 \%$ & $0.58 \%$ & $0.69 \%$ & $4.15 \%$ & $11.11 \%$ & $18.18 \%$ \\
\hline \multicolumn{3}{|c|}{ Panel C: Stock Indices } & \multicolumn{5}{|l|}{ Rolling } & \multicolumn{3}{|c|}{ Standard } \\
\hline Year/Window & 25 & 30 & 50 & 100 & 150 & 25 & 30 & 50 & 100 & 150 \\
\hline 1995 & 9 & 32 & 105 & 156 & 210 & 0 & 1 & 2 & 2 & 4 \\
\hline 1996 & 4 & 5 & 48 & 144 & 261 & 1 & 0 & 0 & 3 & 2 \\
\hline 1997 & 22 & 39 & 159 & 387 & 537 & 1 & 1 & 3 & 2 & 3 \\
\hline 1998 & 18 & 28 & 143 & 569 & 1,164 & 0 & 0 & 2 & 6 & 3 \\
\hline 1999 & 16 & 12 & 68 & 185 & 582 & 2 & 0 & 0 & 1 & 5 \\
\hline 2000 & 9 & 10 & 62 & 282 & 356 & 0 & 0 & 2 & 1 & 2 \\
\hline 2001 & 12 & 22 & 140 & 569 & 705 & 0 & 0 & 2 & 9 & 3 \\
\hline 2002 & 10 & 15 & 64 & 398 & 792 & 1 & 0 & 1 & 5 & 8 \\
\hline 2003 & 5 & 6 & 21 & 185 & 515 & 0 & 0 & 1 & 1 & 1 \\
\hline 2004 & 41 & 58 & 168 & 425 & 709 & 1 & 3 & 2 & 4 & 6 \\
\hline 2005 & 28 & 27 & 73 & 184 & 331 & 3 & 2 & 1 & 1 & 3 \\
\hline 2006 & 3 & 8 & 93 & 497 & 1,141 & 0 & 0 & 3 & 4 & 5 \\
\hline
\end{tabular}




\begin{tabular}{|c|c|c|c|c|c|c|c|c|c|c|}
\hline 2007 & 27 & 34 & 199 & 522 & 862 & 2 & 0 & 6 & 7 & 5 \\
\hline 2008 & 20 & 36 & 243 & 903 & 1,283 & 2 & 1 & 3 & 11 & 8 \\
\hline 2009 & 16 & 15 & 16 & 366 & 856 & 0 & 0 & 0 & 2 & 5 \\
\hline 2010 & 16 & 18 & 68 & 426 & 816 & 0 & 0 & 0 & 4 & 6 \\
\hline 2011 & 32 & 51 & 218 & 585 & 1,001 & 0 & 3 & 4 & 6 & 8 \\
\hline 2012 & 15 & 21 & 65 & 229 & 622 & 0 & 0 & 2 & 3 & 3 \\
\hline 2013 & 28 & 42 & 47 & 17 & 134 & 1 & 0 & 2 & 0 & 1 \\
\hline NL windows & 331 & 479 & 2 & 7,029 & 12,877 & 14 & 11 & 36 & 72 & 81 \\
\hline $\begin{array}{l}\text { Total } \\
\text { windows }\end{array}$ & 3,7062 & 3,7022 & 3,6862 & 3,6462 & 3,6062 & 1,486 & 1,238 & 742 & 368 & 246 \\
\hline Percentage & $0.89 \%$ & $1.29 \%$ & $5.43 \%$ & $19.28 \%$ & $35.71 \%$ & $0.94 \%$ & $0.89 \%$ & $4.85 \%$ & $19.57 \%$ & $32.93 \%$ \\
\hline Panel D: CDS & & & Rolling & & & & & Standar & & \\
\hline Year/Window & 25 & 30 & 50 & 100 & 150 & 25 & 30 & 50 & 100 & 150 \\
\hline 2003 & 2 & 35 & 95 & 65 & 1 & 0 & 2 & 0 & 1 & 0 \\
\hline 2004 & 9 & 68 & 271 & 496 & 695 & 1 & 1 & 3 & 7 & 4 \\
\hline 2005 & 5 & 65 & 249 & 477 & 613 & 0 & 1 & 3 & 3 & 5 \\
\hline 2006 & 8 & 61 & 166 & 329 & 379 & 0 & 2 & 2 & 4 & 3 \\
\hline 2007 & 7 & 60 & 194 & 397 & 593 & 0 & 3 & 3 & 3 & 2 \\
\hline 2008 & 6 & 22 & 150 & 294 & 435 & 1 & 0 & 5 & 5 & 3 \\
\hline 2009 & 4 & 57 & 214 & 526 & 673 & 0 & 2 & 4 & 4 & 5 \\
\hline 2010 & 13 & 59 & 220 & 620 & 1,009 & 0 & 4 & 6 & 7 & 8 \\
\hline 2011 & 21 & 70 & 168 & 438 & 731 & 1 & 2 & 5 & 4 & 4 \\
\hline 2012 & 27 & 30 & 78 & 251 & 295 & 0 & 2 & 3 & 2 & 1 \\
\hline 2013 & 0 & 0 & 0 & 96 & 102 & 0 & 0 & 0 & 1 & 2 \\
\hline NL windows & 102 & 527 & 1,805 & 3,989 & 5,526 & 3 & 19 & 34 & 41 & 37 \\
\hline $\begin{array}{l}\text { Total } \\
\text { windows }\end{array}$ & 4,292 & 6,793 & 9,095 & 8,845 & 8,595 & 173 & 229 & 184 & 92 & 60 \\
\hline Percentage & $2.38 \%$ & $7.76 \%$ & $19.85 \%$ & $45.10 \%$ & $64.29 \%$ & $1.73 \%$ & $8.30 \%$ & $18.48 \%$ & $44.57 \%$ & $61.67 \%$ \\
\hline
\end{tabular}

We now repeat the calculations, only this time we modify the number of observations for each window, finding that under both methodologies (standard and rolling), the size of the window has a relevant impact on the total number of nonlinear windows that the Hinich test can detect. For example, using a window whose size is 50 observations, the standard methodology finds, 15, 25, 36 and 34 nonlinear windows for series of Commodities, Exchange Rates, Stock Indices, and CDS, respectively. However, when the rolling methodology is used on the same series, the results produce 652, 1138, 2000 and 1805 nonlinear windows respectively. When using both the standard as well as the rolling methodologies there is an important increase in the number of nonlinear windows that the Hinich test is capable of detecting within all of the financial assets studied,

The first important aspect that we can extract from this point is that the results of the Hinich test are sensitive to the size of the window used to detect nonlinear processes in financial series, both when using the standard methodology as well as 
the rolling methodology. Additionally, we don't observe significant differences in the percentage of the number of nonlinear windows with respect to the total number of windows for each series, comparing both methodologies for a window of the same size. The second important aspect is that the nonlinear processes present themselves in different manners among the different financial assets, and that they are sensitive, once again, to a change in the size of the window used to detect these processes.

When we consider the percentage number of nonlinear windows with respect to the number of total windows, and using the traditional window size of 25 observations, we see that for series of Commodities, Exchange Rates, Stock Indices, and CDS, the results are $1.11 \%, 0.58 \%, 0.94 \%$ and $1.73 \%$ respectively when using the standard methodology. The results using the rolling methodology, however, are $0.77 \%, 0.48 \%, 0.89 \%$ and $2.38 \%$ respectively. In other words, the percentage number of nonlinear windows with respect to the total number of windows is different for each type of financial asset when using both methodologies, as was mentioned previously. When we change the size of the window to 50 observations, the results for series of Commodities, Exchange Rates, Stock Indices, and CDS, are $4.81 \%, 4.15 \%, 4.85 \%$ and $18.48 \%$ respectively when using the standard methodology. When we use the rolling methodology the results for the same series are $4.20 \%, 3.79 \%, 5.43 \%$ and $19.85 \%$ respectively. When using both methodologies we see an increase in the percentage of nonlinear windows with respect to the total number of windows. On a market level, however, only the change in percentage of the CDS presents an important difference with respect to the other financial assets. Finally, the differences between the markets are more obvious when the size of the window is 150 observations. For example, the results for series of Commodities, Exchange Rates, Stock Indices, and CDS, are 20.39\%, 18.18\%, 32.93\% and $61.67 \%$ respectively when using the standard methodology. Thus, regarding this point we are able to conclude that the number of observations included in the window when using the Hinich test not only impacts on the amount of nonlinear windows that this test detects, but also on the percentage of nonlinear windows with respect to the total amount of windows it is capable of detecting. At the same time, when the size of the window increases, the difference between different markets also increases. To summarize, the amount, as well as the percentage of nonlinear windows, for each financial assets series differs more strongly if the size of the window increases, using both methodologies. At first we believed that some component of the sample could be altering the results. Because of this, we analyzed the number of nonlinear windows and the percentage of nonlinear windows compared to the total number of windows for each asset. We didn't observe any important difference between the assets within each market. It may be that the depth and width of the markets, as well as their compositions, participants and regulations, could explain these differences, for example. This question is not part of what is being analyzed in this paper, but is outlined as a future investigative line. 


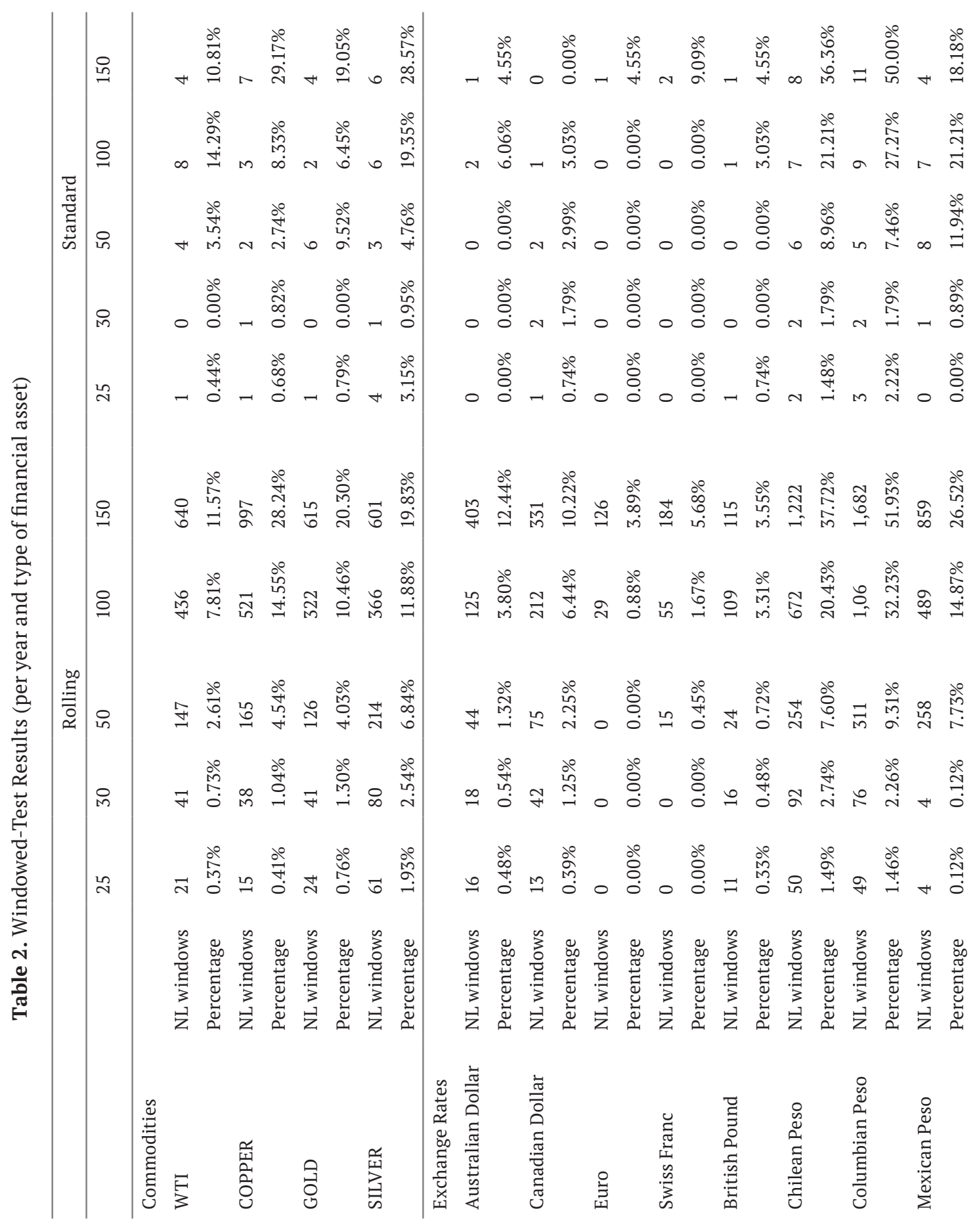




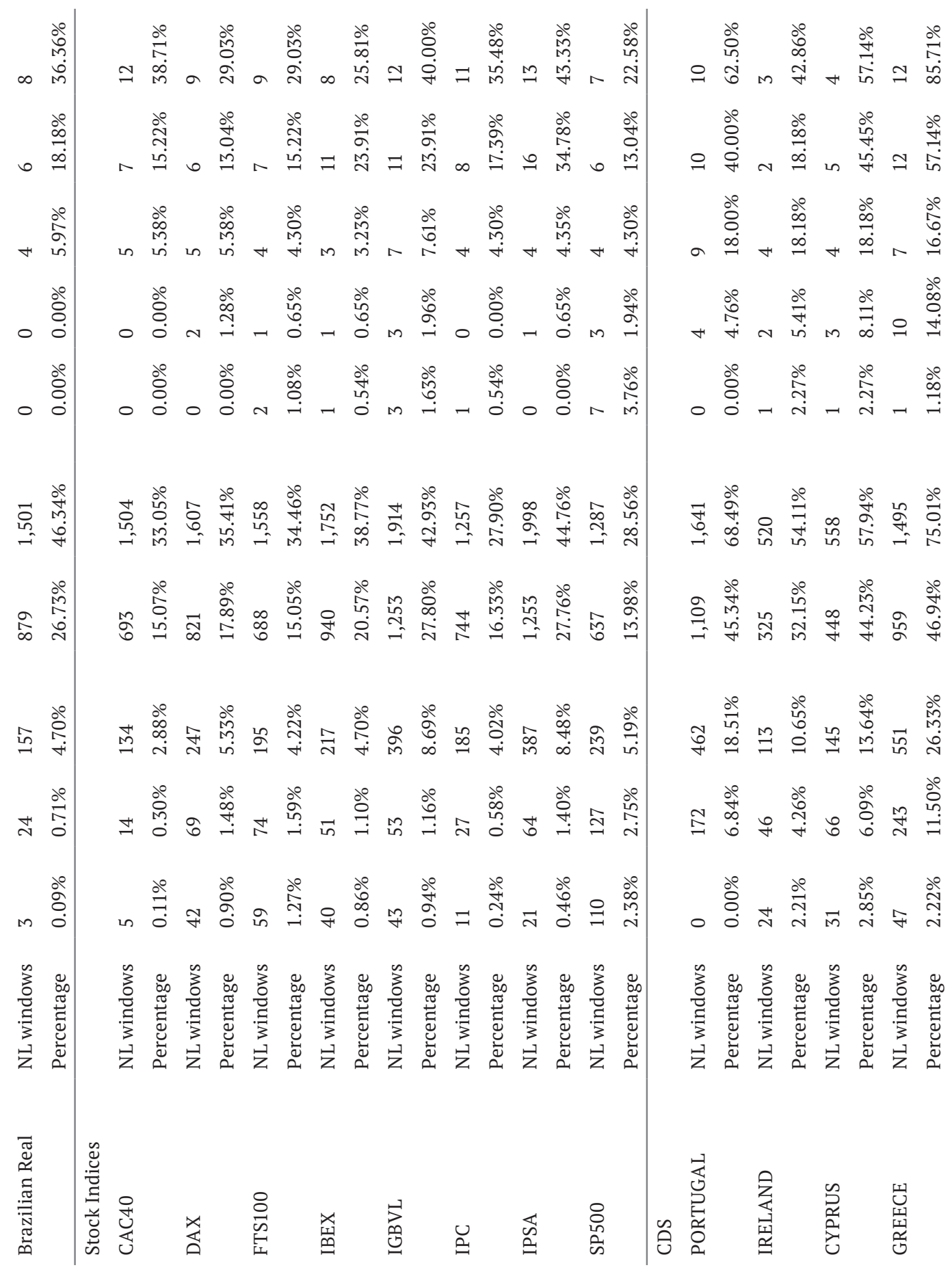


Finally, we analyzed the nonlinear behavior of these series on a year to year basis. We observed the same differences between standard and rolling methodologies, as well as the existence of a window size effect. We did not find a clear pattern that could explain the nonlinear behavior in financial series at an aggregate level. This nonlinear behavior appears more strongly for some series in some years, while for other financial series assets this behavior is more pronounced in other years. Apparently, the differences in structure of each market could also explain the differences between years. This is another topic of investigation.

\section{Conclusions}

In this article, using series of Commodities, Exchange Rates, Stock Indices, and CDS, we present evidence that the nonlinear episodes in financial series are more permanent than transitory. To this end, and unlike the traditional methodology used to estimate the Hinich test, we used overlapping windows which is equivalent to using a rolling methodology. The rolling methodology is more realistic than the standard methodology because the agents adapt their decisions as new information appears, in line with the adaptive markets hypothesis (Lo, 2004; Lo, 2005). When using this methodology we find a significant increase in the number of nonlinear windows with respect to the standard methodology, which leads us to state that nonlinear episodes in financial series are more permanent than transitory.

In the second part, we modified the number of observations of the window used in the Hinich test to detect non-linearity and found that under both methodologies (standard and rolling), the size of the window has a relevant impact on the total number of nonlinear windows as well as the percentage of nonlinear windows that the Hinich test can detect. This confirms the window size effect reported by Espinosa et al. (2014). Additionally, modifying the size of the window makes the nonlinear episodes very different between the different financial markets, as well as between the years within each market and among markets.

The results clearly show that the Hinich test results are sensitive to the size of the chosen window; that the rolling methodology is conducive to detecting a larger number of nonlinear episodes; and, that nonlinear episodes in financial series remain an unsolved puzzle.

\section{References}

Abhyankar, A., Copeland, L. and Wong, W. (1995). Nonlinear dynamics in realtime equity market indices: evidence from the United Kingdom. Economic Journal 105, 864-80.

Ammermann, P. and Patterson, D. (2003). The cross-sectional and cross-temporal universality of nonlinear serial dependencies: evidence from world stock indices and the Taiwan Stock Exchange. Pacific-Basin Finance Journal, 11, 175-95.

Bonilla, C., Romero-Meza, R. and Hinich, M. (2006). Episodic nonlinearity in Latin American stock market indices. Applied Economics Letters, 13, 195-9.

Bonilla, C., Maquieira, C. and Romero-Meza, R. (2008). Nonlinear behavior of 
emerging market bonds spreads: the Latin American case. Applied Economics 40, 2697-2702.

Bonilla, C., Romero-Meza, R. and Maquieira, C. (2010). Nonlinearities and GARCH inadequacy for modeling stock market returns; empirical evidence from Latin America. Macroeconomic Dynamics, 1-12.

Bonilla, C.A., Romero-Meza, R. and Gutierrez, E. (2011) Episodic Nonlinearities and Market Efficiency in the Mexican Stock Market, The Manchester School, 79, 367-380.

Brooks, C. Hinich, M.J. and Molyneux, R. (2000), “Episodic nonlinear event detection: Political epochs in exchange rates”, In: D. Richards (Ed.), Political complexity: Political epochs in exchange rates, Ann Arbor, MI: Michigan University Press, pp. 83-98.

Brooks, C. (1996). Testing for nonlinearity in daily sterling exchanges rates. Applied Financial Economics 6, 307-17.

Brooks, C. and Hinich, M.J. (1998). Episodic nonstationarity in exchange rates, Applied Economics Letters 5, 719-722.

Espinosa, C., Gorigoitía, J. and Maquieira, C. (2013). Comportamiento no lineal en series de productos primarios. El Trimestre Económico, vol. LXXX (1), issue 317, pages 143-168.

Espinosa, C., Gorigoitía, J. Maquieira, C. and Vieito, J. (2014). Non-Linear Behaviour in EMBI series from Eastern Europe: Evidence of "window size effect". Applied Economics Letters 21(2), 107-112.

Hinich, M. (1996). Testing for dependence in the input to a linear time series model. Journal of Nonparametric Statistics 6, 205-21.

Hinich, M. and Patterson, D. (1985). Evidence of nonlinearity in daily stock returns. Journal of Business and Economic Statistics 3, 69-77.

Hsieh, D. (1991). Chaos and nonlinear dynamics: application to financial markets. Journal of Finance 46, 1839-77.

Kosfeld, R. and Robé, S. (2001). Testing for nonlinearities in German bank stock returns. Empirical Economics 26, 581-97.

Lim, K. and Hinich, M. (2005). Cross-temporal universality of nonlinear serial dependencies in Asian stock markets. Economics Bulletin 7, 1-6.

Lim, K. P., Brooks, R. D. and Hinich, M. J. (2006). Testing the assertion that emerging Asian stock markets are becoming more efficient. SSRN Working Paper Series.

Lim, K. P., Brooks, R. D. and Hinich, M. J. (2008). Nonlinear serial dependence and 
the weak-form efficiency of Asian emerging stock markets. Journal of International Financial Markets, Institutions and Money, Elsevier, vol. 18(5), 527-544.

Lo, A. W. (2004). The Adaptive Markets Hypothesis: Market Efficiency from an Evolutionary Perspective. Journal of Portfolio Management, 30, pp. 15-29.

Lo, A. W. (2005). Reconciling efficient markets with behavioral finance: the Adaptive Markets Hypothesis. Journal of Investment Consulting 7(2), pp. 21-44.

Opong, K., Mulholland, G., Fox, A. and Farahmand, K. (1999). The behavior of some UK equity indices: an application of Hurst and BDS tests. Journal of Empirical Finance $6,267-82$.

Scheinkman, J., and LeBaron, B. (1989). Nonlinear dynamics and stock returns. Journal of Business 62, 311-37.

Todea, A. and Zoicas-Ienciu, A. (2008). Episodic dependencies in central and Eastern Europe stock markets, Applied Economics Letters, 15, 1123-1126. 